\title{
A Dashboard for Online Pricing
}

\author{
Michael R. Baye \\ Kelly School of Business \\ Indiana University \\ J. Rupert J. Gatti \\ Faculty of Economics \\ University of Cambridge \\ Paul Kattuman \\ Judge Business School \\ University of Cambridge \\ John Morgan \\ Haas Business School \\ University of California, Berkeley \\ Preliminary Draft, December 2006
}

The authors thank the Economic and Social Research Council and the National Science Foundation for financial support. All views and opinions are those of the authors and not those of ESRC or the NSF. 


\section{Introduction}

At the beginning of the online era, many pundits-including The Economist-concluded that the online retail industry was an unpromising one for firms seeking competitive advantage:

The explosive growth of the Internet promises a new age of perfectly competitive markets. With perfect information about prices and products at their fingertips, consumers can quickly and easily find the best deals. In this brave new world, retailers' profit margins will be competed away, as they are all forced to price at cost. (The Economist, November 20, 1999, p. 112)

Things have not quite turned out the way the The Economist predicted. Prices have not been driven to marginal cost—indeed, the "law of one price" does not hold in online markets. ${ }^{1}$ Moreover, major players with identifiable brands and pricing power over consumers, such as Amazon, have emerged from the sea of competitors in both US and European online markets.

What innovations in pricing strategy are required for a firm to be successful in an e-retail market? This paper uses insights gleaned from five cases studies of pricing in online markets to highlight several innovative pricing strategies for e-retailers. The cases are drawn from the experiences of online retailers at the price comparison site, Kelkoo. A subsidiary of Yahoo!, Kelkoo boasts over 10 million visits per month from consumers within the UK alone, and is the largest price comparison site in all of Europe. We conclude by offering a "dashboard" for online pricing - a set of tools for assessing (and possibly reshaping) pricing strategies in the highly dynamic online environment - based on the lessons drawn from the cases.

While our focus is on innovative pricing strategies for online markets, the prerequisites

\footnotetext{
${ }^{1}$ Michael R. Baye, John Morgan, and Patrick Scholten, "Information, Search, and Price Dispersion," Handbook of Economics and Information Systems (forthcoming), T. Hendershott, ed., North Holland: Elsevier, survey 20 different studies that document levels of price dispersion of 20 to 40 percent in online markets in the US and abroad.
} 
for competitive advantage in offline markets are still operative in online space. ${ }^{2}$ Brand recognition, firm reputation, and store location (placement on the screen) are important to a successful online business. However there are unique features of online markets that necessitate innovations relative to traditional offline markets, and it is important to assess how these features impact successful online pricing strategies.

The online marketplace differs from physical markets in a number of significant respects. One of the most important differences is the ease with which online consumers and rival retailers may access comparative information about seller characteristics and prices. ${ }^{3}$ The fact that search engines, shopbots and price comparison sites provide both consumers and firms with a wealth of information - merely at the cost of a click - is a two-edged sword. While consumer access to price information tends to sharpen price competition, firms' access to this information creates opportunities for innovative pricing strategies that are not generally feasible (or even necessary) in offline markets.

Online customers often search at the product level rather than by store. By the time a consumer is ready to make a purchase, she will likely have compared a variety of attributes, including prices, at alternative e-retail outlets. This fundamentally changes the nature of competition faced by e-retailers, who increasingly compete at the individual product level rather than across broad product categories. Consumers are much more selective in online markets; specialization in the provision of niche products, where competition may be weaker, can be a profitable strategy in online markets. Thus, in contrast to offline markets, pricing and yield management strategies in online markets must be product specific. For offline firms looking to tap into online markets, a fundamental rethinking of time-honored pricing policies - such as applying the same markup to similar products sold at the store-is required. The timing and tailoring of prices to specific models of products is the key to successful pricing in online markets.

In online markets, it is technically feasible - and as we shall see below, strategically

\footnotetext{
${ }^{2}$ See, for instance, Hal Varian and Carl Shapiro, Information Rules (1998), Harvard Business School Press.
} 
desirable - to frequently change the prices of individual products. With the tempo of price changes by competitors' being measured in days rather than weeks, price management requires a dashboard to monitor and respond to the dynamic nature of online markets.

To summarize, online markets are considerably more fluid than their offline counterparts because consumers are increasingly searching for specific models of products. Additionally, the number of rivals selling a particular product - and their prices - change almost daily. Further adding to the dynamics, for many products sold online the pace of technological change translates into dramatically shortened product life-cycles. A onesize-fits-all pricing policy, prescribed from on high, is unlikely to yield satisfactory results in online markets. As we shall see, successful e-retailers use a variety of innovative, dynamic, product-specific pricing strategies.

\section{Determining the Optimal Markup}

It is apparent that, if one is to profitably compete in any marketplace—online or off-one needs to set a price that is above the incremental cost leading to a sale. Incremental costs include the wholesale price of the item and, in the e-retail setting, expected clickthrough fees paid to platforms. As the market capitalization of Google attests, the costs of clickthroughs are considerable and should not be neglected. For instance, clickthrough fees on price comparison sites range from around 40 cents to $\$ 1.50$ or more. Moreover, the conversion rate (the probability that a click results in a sale) is quite low for most products, averaging about $3 \% .{ }^{4}$ Put bluntly, it takes many clicks to obtain a sale and the costs of the clicks must be accounted for in pricing.

As an example, consider an online retailer that obtains an item at a wholesale price of $\$ 50$ and sells it at a price comparison site that charges $\$ 0.50$ per click and boasts a conversion

\footnotetext{
${ }^{3}$ Online information can also have spillover effects for pricing in offline markets; see Meghan Busse, Jorge Silva-Risso, and Florian Zettelmeyer, "\$1000 Cash Back: The Pass-Through of Auto Manufacturer Promotions" (2006), American Economic Review, Vol. 96 (4), pp. 1253-1270.

${ }^{4}$ See, for instance, "Comparison Search Engines Tested," http://www.marketingexperiments.com (November 14, 2006).
} 
rate of $5 \%$. Since an average of 20 clicks $(=1 / 0.05)$ are needed to generate a sale, the firm's incremental cost of each sale is $\$ 60(=\$ 50+\$ 0.5 \times 20)$.

Of course, properly accounting for clickthrough fees in computing relevant incremental costs is only one piece of the pricing puzzle. At least as important is the question of how much above incremental cost to set the price. Here, the crucial factor is the price sensitivity of consumers. The optimal markup factor will be lower on items for which consumers are more price sensitive and higher for products where consumers are less price sensitive.

A standard measure of price sensitivity is the price elasticity of demand:

$$
\varepsilon=\frac{\% \text { change in sales }}{\% \text { change in price }}
$$

For instance, a firm with a price elasticity of -4 would enjoy a $4 \%$ increase in units sold if it decreased its price by $1 \%$. On the other hand, if that same firm faced a price elasticity of -10 , then a $1 \%$ price reduction would increase units sold by $10 \%$.

The optimal markup factor is simply ${ }^{5}$

$$
\text { Optimal Markup Factor }=\frac{\varepsilon}{1+\varepsilon}
$$

Thus, if the price elasticity is -4 , then the optimal markup factor is 1.33 . If consumers are more price sensitive, such that the elasticity is -10 , the optimal markup factor is 1.11 .

- The optimal markup for a product depends on the price sensitivity of consumers, and may be quantified by the product's price elasticity of demand. 
The optimal price is simply

$$
\text { Optimal Price }=\text { Incremental Cost } \times \text { Optimal Markup Factor } .
$$

Of course, to operationalize this pricing policy, managers need to develop a set of tools and metrics for determining not only the price sensitivity of consumers, but pricing strategies that that reflect the dynamic nature of online markets. Thanks to the ready availability of data in online markets, a pricing manager can easily approximate the elasticity of demands for the different products it sells online. To see this, let $q_{0}$ be the firms' sales of a product when the price is $p_{0}$, and $q_{1}$ be its sales at a different price, $p_{1}$. Then the following can be used to obtain a simple estimate of the elasticity of demand for the product:

$$
\varepsilon=\left(\frac{q_{1}-q_{0}}{q_{1}+q_{0}}\right)\left(\frac{p_{1}+p_{0}}{p_{1}-p_{0}}\right)
$$

For example, a firm that sold 10 units at a price of $\$ 100$ but only 6 units when it experimented with a $\$ 120$ price would estimate a price elasticity of $\varepsilon=-2.75$, leading to an optimal markup factor of 1.57 .

More refined estimates may be obtained by using sophisticated statistical techniques to control for other relevant factors that impact price sensitivities. However, the point to remember is that even the best of these techniques are useless without price experimentation on the part of the firm. Without price changes, data on sales will be insufficient to identify the price sensitivity of consumers. Some degree of ongoing price experimentation is valuable, as it provides important information about how price sensitivities change over time.

\footnotetext{
${ }^{5}$ See, for instance, Michael R. Baye, Managerial Economics and Business Strategy (2006), New York: McGraw-Hill, p. 401.
} 


\section{- Conduct periodic price “experiments" to gauge how price sensitivities are}

changing over time.

\section{Case 1: Pixmania Uses Price Experimentation to Learn its Customers’ Price Sensitivity}

Pixmania is a large European e-retailer that understands the value of price experimentation. Pixmania offers over 10,000 consumer electronics items, and uses Kelkoo as a platform to drive customers to its products. Consider Pixmania's pricing pattern for the Palm Tungsten T3 PDA, which is displayed in Figure 1. For the 14 week period depicted in the figure, Pixmania adjusted its product price 11 times, with prices ranging from a low of $£ 268$ to a high of $£ 283$. There is no discernible trend in the pricing pattern-Pixmania essentially conducted a series of small experiments that enabled it to learn about the price sensitivities of its customers. As we will see below, Pixmania's pricing strategy also provides an additional strategic benefit-unpredictability.

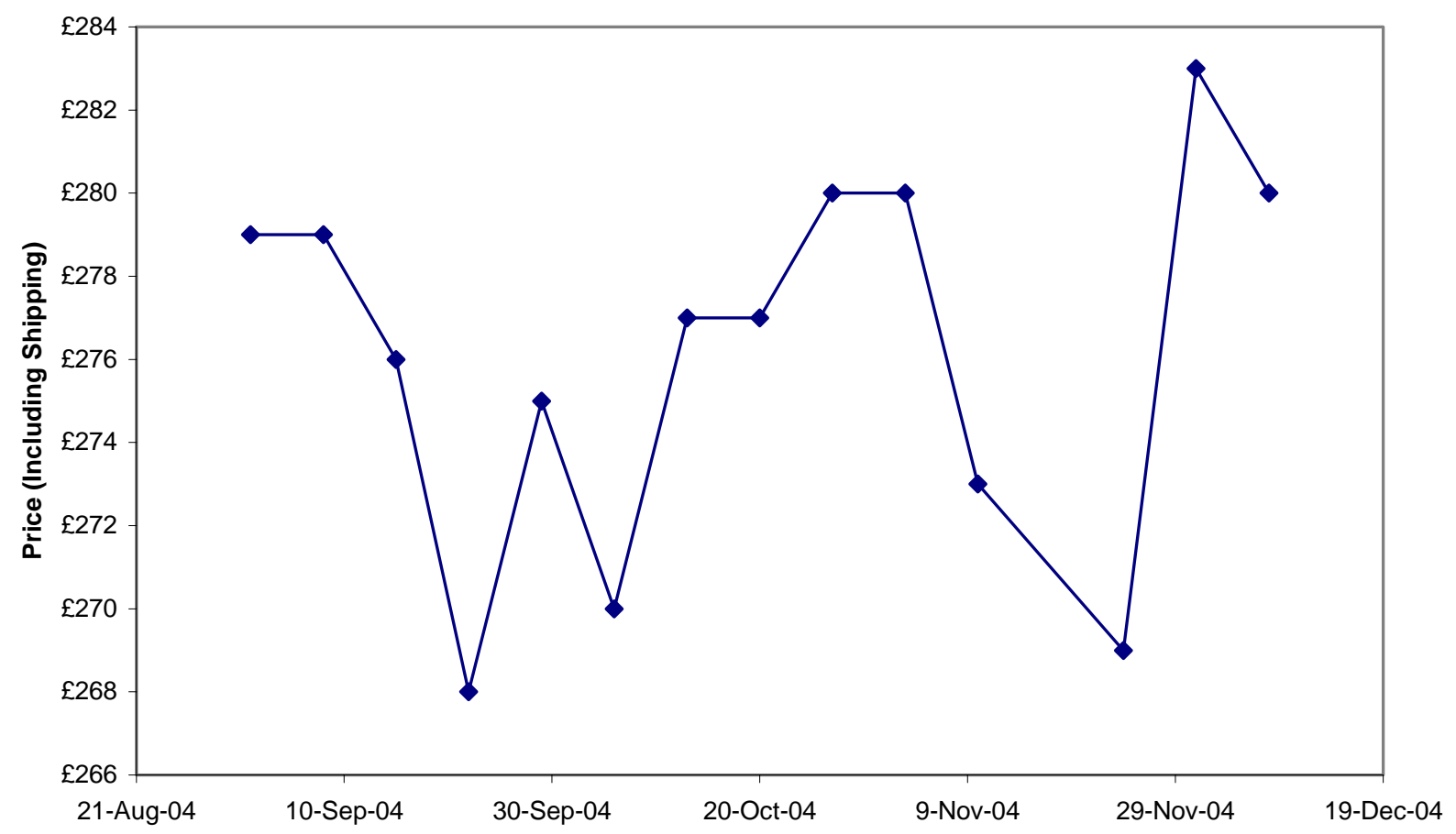

Figure 1: Pixmania experiments with its pricing of the Palm Tungsten T3 to learn the price sensitivity of its customers. 


\section{Factors that Influence Price Sensitivity}

\subsection{Product Life-Cycles.}

Most products have clear life-cycles, particularly when viewed at the level of a specific model. For most products - including consumer electronics, books, and fashion items early buyers are the least price sensitive, while buyers who delay their purchases tend to be more price sensitive. A firm seeking to hone in on an item's optimal price must monitor the price sensitivities of consumers throughout the product's life-cycle in order to dynamically adjust the product's markup. The ease with which online shoppers can learn about new products - and seek out vendors that are selling the latest model - tend to make product life cycles significantly shorter for products sold online, and necessitate fairly rapid reductions in markups.

- In many online markets, the length of a product life cycle is measured in weeks rather than months or years. Optimal pricing requires an online seller to continually monitor price sensitivities and stand ready to quickly reduce markups as a product's life-cycle evolves.

Importantly, these price reductions are called for even if there are not reductions in wholesale prices; the optimality of price reductions stem from reductions in price sensitivities throughout the product life cycle. To the extent that wholesale prices also decline throughout a product's life cycle, additional price reductions are warranted.

\section{Case 2: C\&A Electronics Optimizes Prices over the Life Cycle}

Our next case study illustrates how two online retailers - Comet and C\&A Electronicspriced a popular PDA during its relatively short life-cycle. Comet is the second largest consumer electronics retailer in the UK, with over 250 retail outlets and annual sales exceeding $£ 1.5$ billion. It has a strong online presence and is one of the most frequently visited consumer electronics websites in the UK. In contrast, C\&A Electronics is the online arm of a small brick-and-mortar consumer electronics retailer, with outlets only in 
London.

The PDA - a Hewlett Packard iPAQ 5550 Pocket PC — was first introduced in the UK during the summer of 2003. At the time of introduction, it was positioned at the top end of the market, thanks to its state-of-the-art specifications and positive reviews.

As Figure 2 shows, C\&A accounted for the product life-cycle in its pricing strategy. As price insensitive early adopters vanished from the market and new and more powerful PDAs appeared on the scene, C\&A lowered its price. Comet, on the other hand, started out at with a slightly lower price than C\&A when the product was first introduced, but essentially maintained this price throughout the year. By September 29, a price differential of over $£ 50$ had emerged. At that point, rather than adjust its price for the aging product, Comet stopped selling the product altogether.

This case illustrates the importance of product-specific pricing policies. By pricing dynamically and accounting for life-cycle effects, C\&A managed to outmaneuver Comet. 


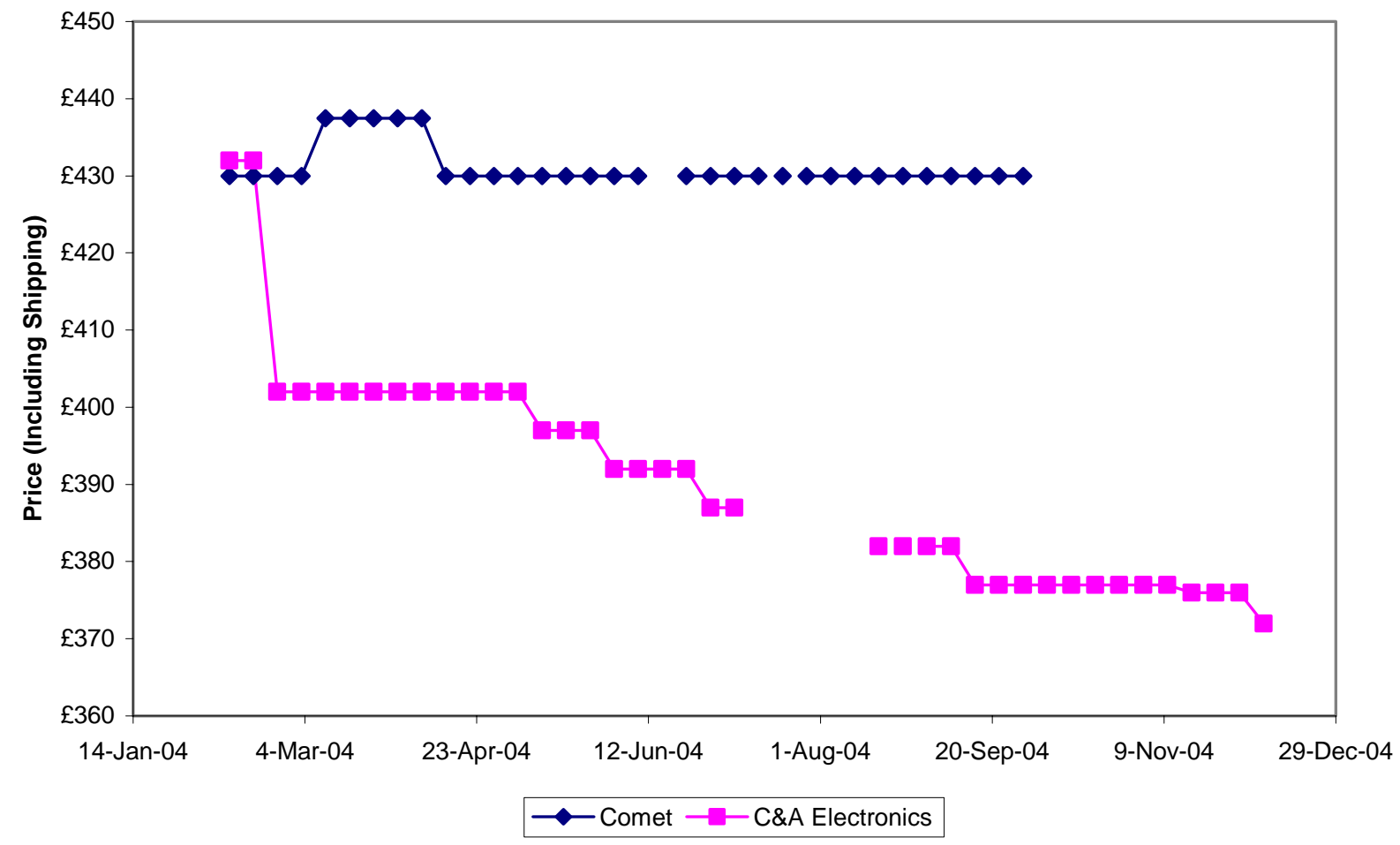

Figure 2: C\&A adjusted its price for the HP IPaq H5550 throughout the life-cycle, fine-tuning the markup to changing price sensitivities of consumers. Comet did not and, as a consequence, was outmaneuvered.

\subsection{Number of Competitors}

As a rule of thumb, the elasticity of demand for a firm's product is proportional to the number of firms offering the product.

- When the number of competing sellers doubles, a firm's elasticity of demand doubles, and its optimal markup declines.

To illustrate, consider an e-retailer that is the only seller listing a product on the price comparison site. Based on price experimentation, it determines that the price elasticity is -2 . Using the formula for the optimal markup factor, the firm optimally charges a price 
that is twice its incremental cost. When an additional firm lists on the site, the firm can deduce, without any additional experimentation, that its price elasticity has doubled, and that its optimal markup factor has declined to 1.33 .

In physical marketplaces, change in the number of competing firms occurs rarely and the number of competitors is similar across products in the same product category. The online marketplace is much more dynamic, and as a consequence, a strategy of determining markups at the level of product categories can lead to disaster. In particular, at price comparison sites such as Kelkoo, the number of firms selling a given product changes almost daily. Since the number of sellers affects the elasticity and optimal markup, an online retailer needs to monitor the number of competitors it is facing for each product it sells and, and must be prepared to customize its prices in real time in response to changes in the number of competitors.

\section{Case 3: Expansys Prices in Response to Changes in the Number of Competitors}

Expansys is one example of an online retailer that changes prices in response to changes in the competitive landscape. Expansys is a subsidiary of Mobile and Wireless Group - a larger company that sells mobile phones and PDAs throughout Europe.

The left-hand axis of Figure 3 indicates the number of firms offering the Palm Tungsten T3 PDA at the Kelkoo site during the February 2004 through March 2005 period, while the right-hand axis displays the price that Expansys charged for this product. The number of sellers initially increased from 8 (in February) to 18 (in July), and then gradually declined over the course of the year. By the end of December, Expansys was the only firm offering the Tungsten $\mathrm{T} 3$ on the Kelkoo site.

Expansys adjusted its prices throughout the period to reflect changes in the level of competition. It reduced prices consistently until the middle of August (as the number of competitors increased), and then began to slightly increase prices (as the number of competitors decreased). Shortly after becoming the sole retailer offering the product on Kelkoo, Expansys reversed course and increased its price (from $£ 240.85$ to 2245.85 on 
January 12, 2005 and to $£ 257.75$ on February 2, 2005). Due to product life-cycle effects, Expansys' price when it was the only seller in the market on February 2005 was only $£ 12$ lower than the price it charged a year earlier when there were 14 sellers in the market.

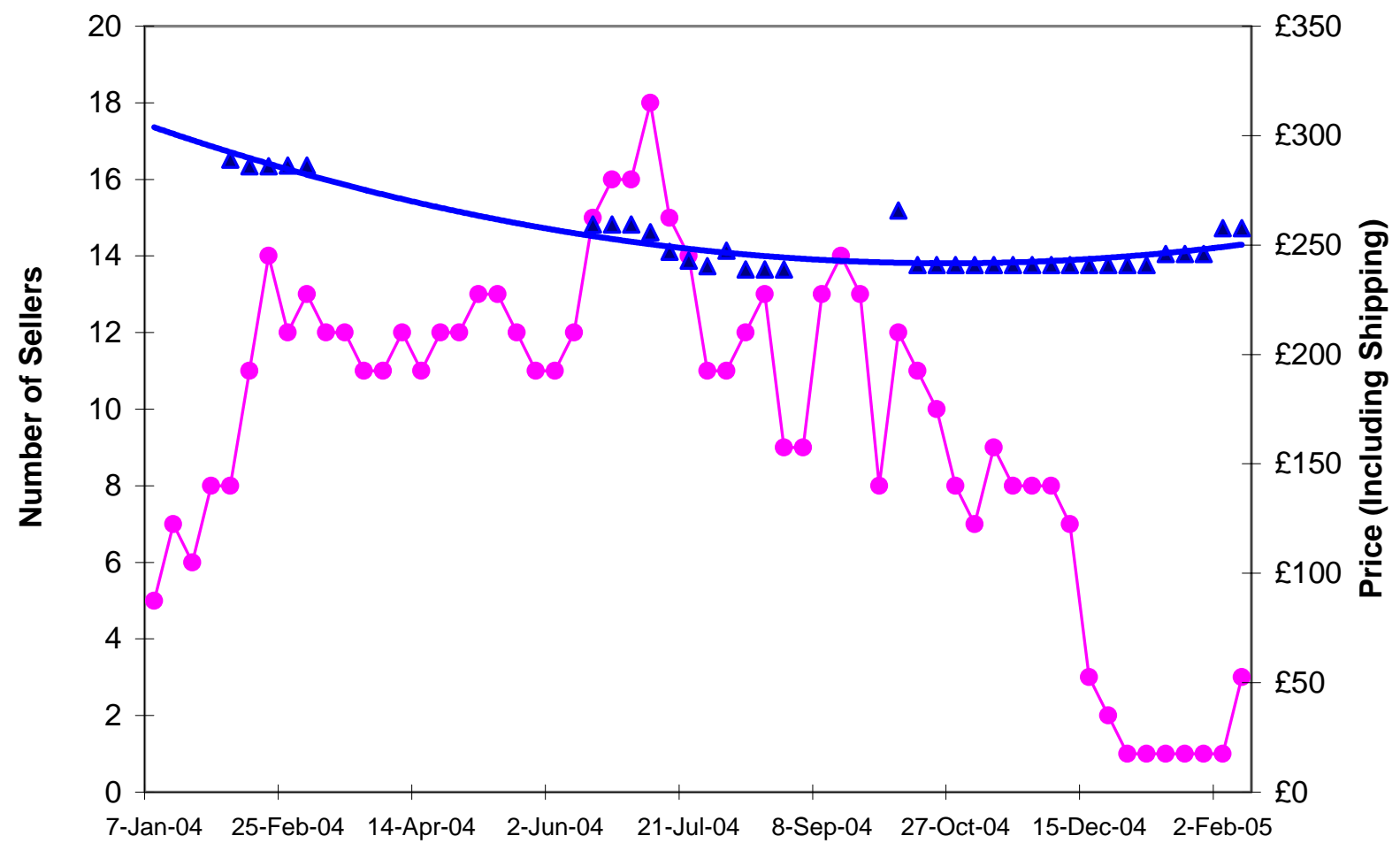

Figure 3: Expansys optimally adjusts its price for the Palm Tungsten T3 to account for changes in the number of competitors and product life cycle effects. 


\section{Strategic Considerations}

\subsection{Stay Unpredictable}

As noted in the Introduction, the ease with prices may be compared online means that not only are consumers better informed - but so are your competitors. Competitors who monitor and are then able to predict your pricing decisions are in a position to capitalize on this information to your detriment. Clearly, every e-retailer must consider its competitors' strategic response to its pricing strategy. For instance, a price reduction that is not matched by competitors is likely to attract more customers, and achieve higher profits, than one that is instantly trumped by its rivals.

One way to keep rivals from responding is to introduce an element of randomness into your pricing strategy. By being unpredictable, your rivals cannot systematically undercut your price or anticipate your next pricing move to act preemptively.

- Strategically injecting uncertainty into the pricing strategy keeps competitors from predicting when, and by how much, you will change prices.

For example, Pixmania's pricing pattern for the Palm Tungsten T3 shown in Figure 1 displays no discernible trend. This makes it difficult for competitors to predict, and systematically undercut, its price. Pixmania's strategy is essentially defensive-it protects itself from exploitation by pricing in an unpredictable fashion. The next case study illustrates the flip side of this idea: A rival whose prices are predictable can be exploited through an offensive strategy of slightly undercutting its price to scoop up the lion's share of the customers.

\section{Case 4: Comet Exploits Predictable Pricing by Tesco}

Comet, the second largest electronics retailer in the UK, was introduced in Case 1. Every week, Comet monitors firms that it considers to be its major competitors (including Tesco) and adjusts its online prices accordingly. Tesco, on the other hand, is the largest 
supermarket chain in the UK, with nearly 2,000 retail outlets and annual sales of over $£ 24$ billion. While Tesco is largely a brick and mortar operation, like other major supermarkets it has expanded its product line and now sells a broad range of items, including consumer electronics, computers, and white goods. It has also moved aggressively into the online space. While Tesco monitors the prices of its three major supermarket competitors, it has a "blind spot" with regard to non-brick-and-mortar rivals.

Figure 4 shows the total prices (including shipping) that Tesco and Comet charged for a Samsung RS21DCS refrigerator, over a seven month period. Due to the predictability in Tesco's pricing strategy, Comet successfully shadowed Tesco's every price move, always managing to undercut it and remain the low price firm offering the product.

The lessons here are clear: Had Tesco used an unpredictable pricing strategy-along the lines of Pixmania's pricing strategy in Figure 1-it could have avoided this trap. In addition, by monitoring only its traditional rivals, Tesco created a "blind spot" that Comet could exploit. Owing to its failure to focus on the set of competitors appropriate to this product in the online space, it is likely that Tesco was completely unaware of its competitive position in this market. 


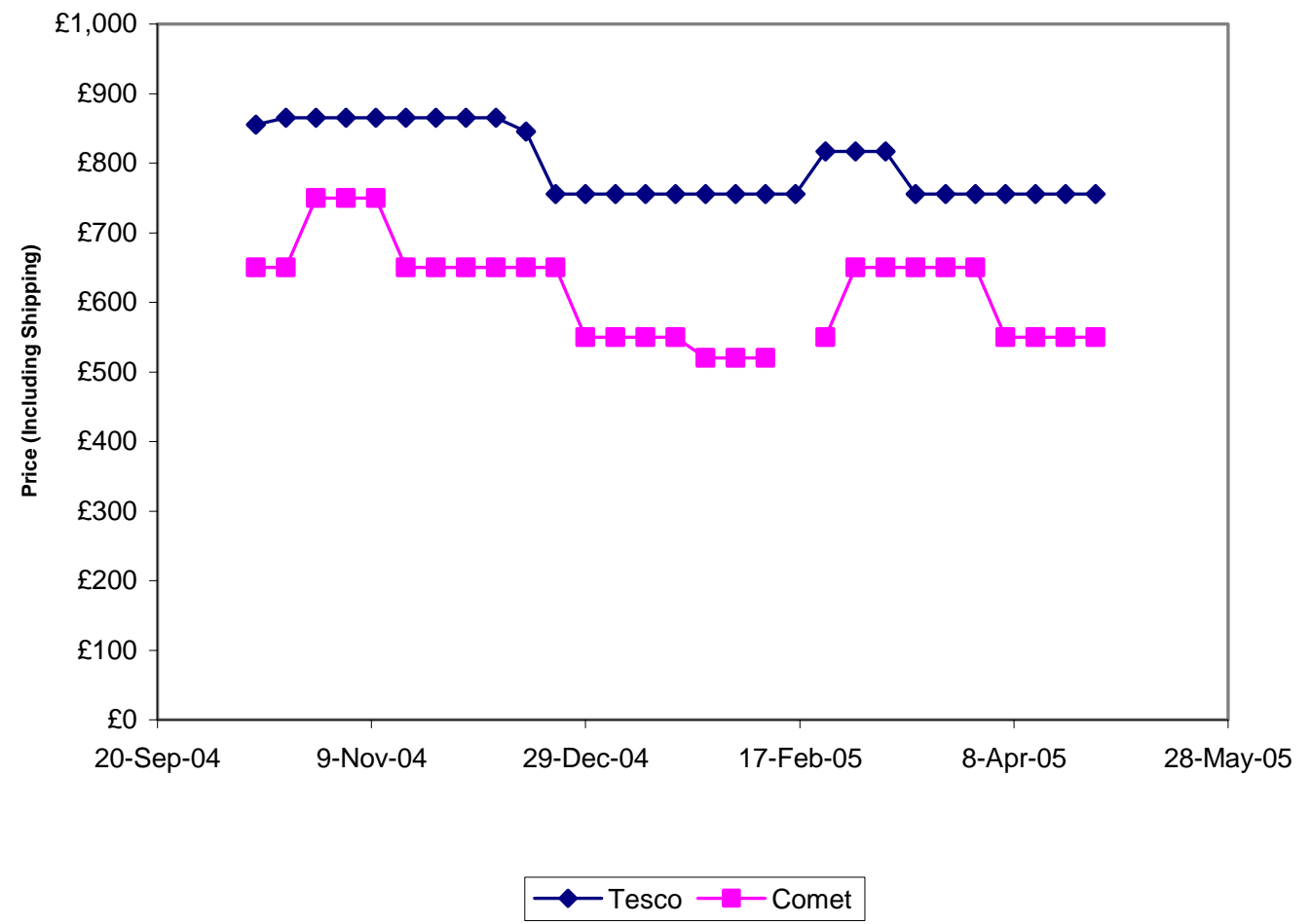

Figure 4 Comet exploits Tesco's predictable price for a Samsung RS21DCS refrigerator to maintain a low price position

\subsection{Use Hit and Run Pricing to Gain a Temporary Advantage without Triggering a Price War}

The success of Comet's undercutting strategy stemmed from Tesco's failure to monitor relevant rivals' prices. When competitors are monitoring, a "hit and run" strategy is called for. ${ }^{6}$

- When rivals are monitoring your price, use a hit and run pricing strategytemporary price undercutting for an unpredictable short interval followed

\footnotetext{
${ }^{6}$ See, for instance, Michael R. Baye, John Morgan, and Patrick Scholten, "Temporal Price Dispersion: Evidence from an Online Consumer Electronics Market," Journal of Interactive Marketing, Vol. 18, No. 4, Autumn 2004, pp. 101-115.
} 


\section{by a return to a higher price point.}

Such a strategy, which reduces the ability of competitors to both anticipate and respond to a price cut, can generate top line growth and raise profits as well. Indeed, an e-retailer may be able to profitably undercut the entire market, and so attract a segment of extremely price sensitive consumers, without inducing a price response from its rivalsprovided that the price reductions are unpredictable and of short duration. Charging a low price for only a short period of time discourages competitors from feeling obliged to match the price reduction, and facilitates price skimming without triggering a price war.

Studies have shown that the firm charging the lowest product price at a price comparison site such as Kelkoo enjoys $60 \%$ more business than a rival that charges only a slightly higher price. $^{7}$ Essentially, the firm charging the lowest price benefits by attracting the extremely price sensitive "shoppers," who make up around $13 \%$ of online consumers. In some instances, the $60 \%$ jump in sales will more than offset the price reduction necessary to gain the position of being the low-price firm. While "running" from this segment by significantly raising price forfeits sales from the price sensitive segment, the margin gains on sales from less price sensitive customers can sometimes still be attractive. Moreover the softened price competition from raising prices is beneficial in the long-run.

A key implication is that offering prices close to, but slightly above, the lowest price in the market is rarely a good strategy since it sacrifices margins on less price sensitive consumers and fails to attract the price sensitive consumers looking for a "bargain." Put succinctly,

\section{- Don't let your price get "stuck in the middle” in an online market.}

\section{Case 5: Comet Uses Hit and Run Pricing}

Comet successfully executed a hit and run pricing strategy for a Hotpoint FFA90

\footnotetext{
${ }^{7}$ See, for instance, Michael Baye, et al., "Clicks, Discontinuities, and Firm Demand Online" (December 2006) Working Paper, University of California, Berkeley, and A. M. Ghose, M. Smith, and R. Telang,
} 
refrigerator over an eight month period. Figure 5 displays the lowest price (including shipping) charged by any of Comet's competitors along with Comet's price. Its rivals, which average 7 over the period, are considerably smaller than Comet, most being purely online retailers with only one maintaining a modest national chain of 15 retail outlets. Consequently, Comet recognized that it was the dominant retailer, and that the other retailers were carefully monitoring its price.

On 31 December 2003 and 31 March 2004, Comet successfully "hit" the market with a dramatic price reduction, undercutting the prices of all of its competitors. In both instances, these price cuts remained in effect for less than two weeks, at which point Comet "ran" back to a significantly higher price. The hit and run nature of Comet's pricing strategy elicited only a limited pricing response from its rivals. On 16 June 2004 Comet struck again - but, unlike previous episodes, the price cut lasted almost a month. This gave rivals an opportunity to respond - and they did. As the figure shows, by the third week, Comet's rivals matched its low price. A week later, Comet "ran" and significantly raised its price.

Both the "hit" and the "run" are critical elements of this strategy. By "hitting" with an unpredictably low price at unpredictable points in time, Comet gained a temporary position as the low price leader in the market. By subsequently "running" and significantly raising its price (as it did following every significant price cut), Comet signaled that it was accommodating and did not intend to engage in a costly price war.

"Internet Exchanges for Used Books: An Empirical Analysis of Product Cannibalization and Welfare Impact," Information Systems Research (2006) 17(1), pp. 3-19. 


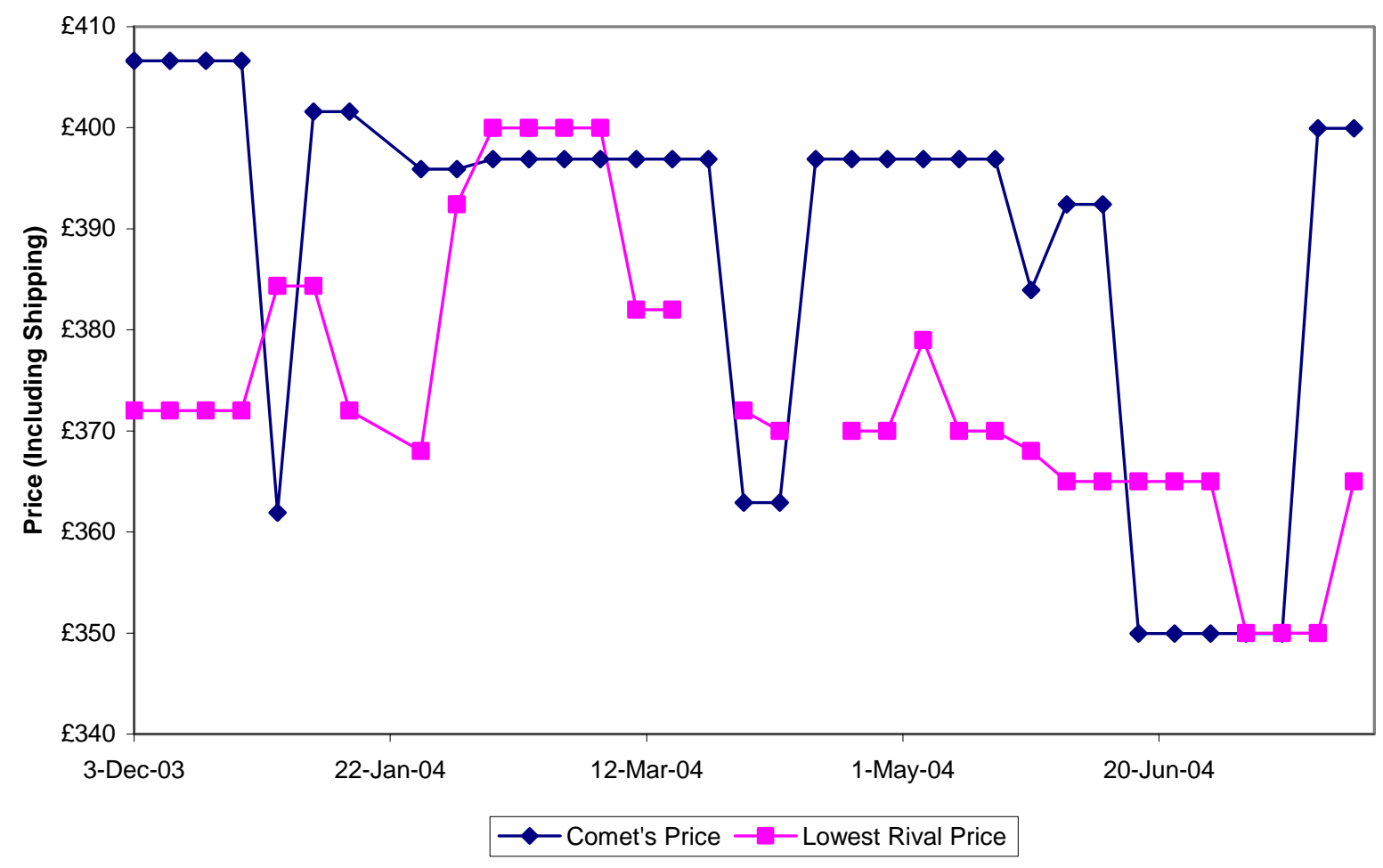

Figure 5: Comet successfully executes a "hit and run" pricing strategy for a Hotpoint FFA90 refrigerator.

\section{Managerial Implications}

Pricing decisions in e-retail markets must be pushed down the managerial hierarchy and conducted at the same level where market information is available. In most cases, this translates into the mass customization of prices - the monitoring of rivals and pricing decisions must be made for specific models of product rather than at the product category level. Firms that do so benefit; firms that do not may be easily exploited by rivals.

To achieve this level of granularity in pricing, a firm must be able to utilize the ample stream of data available about consumer price sensitivities, product life-cycles, the number and prices of rivals, and so on, and quickly integrate these data into metrics useful for determining prices in real time. In short, what is required is a "dashboard" that summarizes the key features of the market for each product, and a strategy for using the 
dashboard to guide pricing decisions.

Table 1 summarizes the dashboard items highlighted in the cases described in this paper.

\begin{tabular}{|l|l|}
\hline Dashboard Item & Implications for Pricing \\
\hline Incremental cost & $\begin{array}{l}\text { Conversion rates and clickthrough fees are a key (and } \\
\text { often neglected) component of incremental cost. }\end{array}$ \\
\hline Number of competitors & $\begin{array}{l}\text { Increase a product's markup when number of rivals } \\
\text { falls, decrease its markup when number of rivals } \\
\text { increases. }\end{array}$ \\
\hline Identity of competitors & $\begin{array}{l}\text { Online competitors may differ from traditional offline } \\
\text { rivals. Don't be blind-sided by an unknown online } \\
\text { competitor. }\end{array}$ \\
\hline Age/new version of product & $\begin{array}{l}\text { Decrease a product's markup at the tail-end of its life } \\
\text { cycle or when new versions are introduced. }\end{array}$ \\
\hline Price sensitivity (elasticity) & $\begin{array}{l}\text { Continuously experiment to learn changes in the price } \\
\text { sensitivity of a product. Apply the optimal markup } \\
\text { factor at the product rather than category or firm } \\
\text { level. }\end{array}$ \\
\hline market & $\begin{array}{l}\text { Be unpredictable if rivals are watching. Exploit } \\
\text { "blind spots" if rivals are not watching. }\end{array}$ \\
\hline thents
\end{tabular}

Table 1: A Dashboard for Online Pricing 
The dashboard consists of a set of key indicators of the competitive landscape on a product by product basis. Of course, the correct pricing strategy is not predetermined. It requires the additional input of skilled managerial expertise to interpret what the dashboard is saying and then to respond appropriately. As with the dashboard on a car, merely knowing how fast your vehicle is traveling is not enough to determine the appropriate driving strategy. For instance, if the speedometer reads $50 \mathrm{mph}$ and you're on a city street, hitting the brakes is the correct response. This same reading from the dashboard on a deserted freeway indicates that you should hit the accelerator.

In the online context, Comet offers an instructive example of the interaction between the dashboard and an optimal pricing strategy. Comet recognized that Tesco was not monitoring its prices for the Samsung RS21DCS refrigerator, and was able to profit from a successful price undercutting strategy. Comet also recognized that its rivals were closely monitoring the prices of the Hotpoint FFA90 refrigerator, and used an entirely different "hit-and-run" pricing strategy to keep its rivals off balance. 